\title{
Üretici Koşullarında Pamukta (Gossypium hirsutum L.) Yaprak Döktürücü Uygulamasının Bazı Morfolojik Özellikler Üzerine Etkisi
}

\section{Rıfkı KABAK ${ }^{1}\left(\mathbb{D}\right.$, Mustafa Ali KAYNAK $^{* 2}$ (D)}

\author{
${ }^{1}$ Burunköy, Söke, Aydın
}

${ }^{2}$ Aydın Adnan Menderes Üniversitesi, Ziraat Fakültesi, Tarla Bitkileri Bölümü, Aydın

Öz: Bu çalışma, üretici koşullarında yaprak döktürücü (defoliant) uygulamalarının pamuğun bazı morfolojik özelliklerine etkisini belirlemek amacıyla, Aydın ili Efeler, Koçarlı, Söke, Didim ve Germencik ilçelerinin köylerinde on üretici tarlasında, 2019 üretim yılında yapılış̧ır. Çalışmada Gloria pamuk çeşidi materyal olarak kullanılmıştır. Deneme tesadüf parselleri deneme desenine göre yürütülmüştür. Çalışmada, defoliant uygulama öncesi toplam koza sayısı, açmış koza oranı ve toplam yaprak sayısı ile defoliant uygulama sonrası açmış koza sayısı ve açmış koza oranı, yeşil yaprak sayısı, bitki üzerinde kalan kuru yaprak sayısı, yaprak döküm oranı, pamuk nem içeriği ve çırçır randımanı özellikleri incelenmiştir. Denemede defoliant uygulama sonrası açmış koza oranı, pamuk nem içeriği özellikleri yönünden üretici uygulamaları arasında istatiksel olarak önemli farkııık olmadığı tespit edilmiştir.Denemede defoliant uygulama öncesi toplam koza sayısı, defoliant uygulama öncesi ve sonrası açmış koza sayısı, defoliant uygulama öncesi yaprak sayısı, defoliant uygulama sonrası bitki üzerinde asılı kalan yeşil yaprak ve kuru yaprak sayısı, defoliant uygulama sonrası yaprak döküm oranı ve çırçır randımanı, özellikleri yönünden üretici uygulamaları arasında istatistiksel olarak önemli farklılıklar olduğu tespit edilmiştir. Çalışmada, bazı üreticilerin defoliant uygulama işlemini gerektiği gibi yapmadığı saptanmıştır.

\section{Anahtar kelimeler: Pamuk, yaprak döktürücü, koza, yaprak}

\section{The Effect of Grower Defoliant Application on Some Morphological Properties of Cotton (Gossypium hirsutum L.)}

\begin{abstract}
This study was carried out in ten grower fields in Aydın, Efeler, Koçarlı, Söke, Didim and Germencik districts in 2019 production year to determine the effect of grower defoliant applications on some morphological properties of cotton. In the study, Gloria cotton variety was used as material. Randomized parcels were conducted according to the trial pattern. In the study, the total number of boll, the number of opened boll and the total number of leaves before the defoliant application; the number of opened bolls after the defoliant application, the rate of opened boll after the defoliant application, the number of green leaves after the defoliant application and the number of dry leaves remaining on the plant, the leaf fall rate, the ginning out-turn, the cotton moisture rate properties were investigated. In the experiment, it has been determined that there is no statistically significant difference between growers' applications in terms of opened boll ratio, cotton moisture rate characteristics after defoliant application. It has been determined that there are statistically significant differences between the applications of the growers in terms of total number of bolls before defoliant application, number of opened bolls before and after defoliant application, number of leaves before defoliant application, number of green leaves and dry leaves remaining on the plant after defoliant application, leaf fall rate after defoliant application, ginning percentage. In the study, it was found that some grower did not perform defoliant application as required.
\end{abstract}

Keywords: Cotton, defoliant, boll, leaf

\section{GiRiş}

Pamuk, dünya tarım ve ticaretinde önemli yere sahip bir endüstri bitkisidir. Tekstil endüstrisi yanında, yağ, yem sanayi ve benzeri birçok alanda önemli bir stratejik konuma sahip olan pamuk gerek insanoğlunun değişen gereksinimleri gerekse sanayide görülen hızlı gelişmeye bağlı olarak, üzerinde çalışmalar yapılan ve her açıdan ele alınarak incelenen bir endüstri bitkisi konumundadır. Pamuk bitkisinin zorunlu ve geniş bir kullanım yelpazesi ile üretiminde istihdam ve devlet hazinesine kattığı değer ile ülke ekonomisinde önemli bir yeri bulunmaktadır. Sınırlı sayıdaki ülkenin ekolojisine elverişliliği de pamuğu önemli bir ticaret ürünü konumuna getirmektedir. Dünya nüfusunun artması ve yaşam standartlarının yükselmesi pamuğa rağbeti yükseltmiştir. Türkiye'de pamuk lifi üretimi, tüketim karşılayamamaktadır. Bu yüzden tekstil sektörü ihtiyacı olan hammadde pamuk lifinin büyük miktarını ithalat ile elde edebilmektedir. Pamuk lifi ithalatında da Dünya'da altıncı ülke konumunda bulunmaktayız (Anonim, 2018). Son yıllarda ülkemizdeki pamuk üretimi artmakta olup, 2018/2019 sezonunda üretimin tüketimi karşılama oranı \%60 seviyesine ulaşmıştır. Ülkemizdeki pamuk fiyatlarının artış göstermesi ve destekleme politikaları sayesinde pamuk üretimi son 3 sezondur artmaktadır. Pamuk üretimi 2018/2019 sezonunda en yüksek üretim

*Sorumlu Yazar: mkaynak@adu.edu.tr Bu çalışma yüksek lisans tez ürünüdür ve Aydın Adnan Menderes Üniversitesi Bilimsel Araştırma Projeleri Koordinasyon Birimi tarafından desteklenmiştir (Proje No: ZRF-19010).

Geliş Tarihi: 12 Şubat 2021

Kabul Tarihi: 06 Nisan 2021 
seviyesine ulaşmış, tüketim de son 30 yılın en yüksek seviyesine ulaşmıştır.

Türkiye'de pamuk üretimi Ege, Antalya, Çukurova ve Güneydoğu Anadolu bölgelerinde yoğunluk gösterir. 2018 yılında ülkemizde üretilen pamuğun $\% 85^{\prime}$ ini karşılayan iller sırasıyla Şanlıurfa (\%40), Aydın (\%11), Hatay (\%10), Diyarbakır (\%9.5), Adana (\%8) ve İzmir (\%6) olmuştur (Anonim, 2018).

Ülkemizde, pamuk hasadında makine kullanımı yaygınlaşmaya başlamasıyla hasada yardımcı kimyasalların kullanımı da artmıştır. Bu kimyasallar yaprak döktürücüler (defoliant), koza açtırııılar, bitki kurutucular ve büyüme durdurucular olarak farklı şekillerde bulunmaktadır. Bu kimyasallar içerdikleri etken maddeler, uygulama dozları ve uygulama zamanı yönünden farklılık göstermekte ve bununla birlikte iklim koşulları (sıcaklık ve yağış) büyük önem arz etmektedir. Günümüzde bu kimyasalların kullanımında bu faktörler dikkate alınmadan yapıldığından istenen sonuçlar elde edilememekte, hasatta verim ve kalite kayıpları yaşanmakta, hasat edilen ürünün işlenmesi sırasında da birçok problemle karşılaşılmaktadır.

Yaprak döktürme uygulaması yağışı periyota girmeden önce hasadın yapılabilmesi için uygulanmaktadır. Amaç, daha hızı koza açılmasını teşvik etme ve yaprakların dökülmesini sağlamaktır. Ülkemizde kullanılan defoliantların verimli çalışabilmesi için sıcaklık değerleri $15{ }^{\circ} \mathrm{C}$ ve üzeri olması gerekmektedir, düşük sıcaklıklarda uygulanan defoliantların etkisi yavaşlamakta ya da durmaktadır. Yağış beklenilen günde defoliant uygulaması yapılmaz, en az bir gün önce yapılmalıdır. Defoliantın yüksek dozda uygulanması yaprakların bitki üzerinde kuruyarak asılı kalmasını ve kütlü pamukta daha fazla yabancı madde (yaprak kalıntısı, çenet, sap parçası vb.) miktarı ile karşılaşılmasını mümkün kılmaktadır. Defoliantın düşük dozlarda kullanılması da yaprakların bitki üzerinde kurumadan, yeşil kalmasına sebep olur ve bu da yabancı madde oranını arttırarak, pamukta kaliteyi düşürmektedir. Makineli hasat ile birlikte defoliant uygulamasının da gereklilik olduğu dönemlerde, üreticilerin defoliant kullanım alışkanlıklarını ve uygulama farklılıkları arasında oluşabilecek sonuçların etkisini görmek için deneme Aydın ilinin farklı ilçelerinde kurulmuştur. Çalışma, aynı pamuk çeşidinin farklı üretim uygulamaları, farklı defoliant uygulamaları ve farklı bölgelerde verdiği tepkileri incelemek için yürütülmüştür. Daha önce yapılan defoliant çalışmaları bir deneme alanında yapııırken, bu çalışma doğrudan üretici koşullarında gerçekleştirilmiştir. Bu çalışma, üretici koşullarında yaprak döktürücü uygulamalarının pamuğun bazı morfolojik özelliklerine etkisini belirlemek amacıyla yapılmıştır.

\section{MATERYAL VE YÖNTEM}

Çalışmada, Gossypium hirsutum L. türüne ait ve bölgemizde en fazla üretimi yapılan standart pamuk çeşitlerinden biri olan Gloria pamuk çeşidi bitki materyali olarak kullanılmıştır.

Çalışma, 2019 yılı üretim yılında, Aydın ili, Efeler, Söke, Koçarlı, Germencik ve Didim ilçelerinde bulunan on üretici arazisinde yürütülmüştür. Çalışma tesadüf parselleri deneme desenine göre tek faktörlü olarak yürütülmüştür. Arazilerde yapılan kültürel işlemler ile birlikte defoliant uygulamasından en fazla 1-2 gün öncesi koza ve yaprak sayımları yapılmış, hasat günü bütün denemelerde tekrar sayım yapılmış ve kütlü pamuk numuneleri alınmış, diğer hasat bilgileri de kayıt altına alınmıştır.

Çalışmada, 1.Üretici, taban gübresi kullanmamıştır. Üst gübrelemede $30 \mathrm{~kg} / \mathrm{da}$ üre (\%46 N) ve $25 \mathrm{~kg} / \mathrm{da}$ amonyum sülfat (\%21 N) kullanmıştır. 2.Üretici, taban gübresi kullanmamıştır. $27 \mathrm{~kg} /$ da üre (\%46 N), ardından $25 \mathrm{~kg} / \mathrm{da}$ amonyum sülfat (\%21 N) vermiştir. 3.Üretici, taban gübresi olarak $10 \mathrm{~kg}$ Diamonyum fosfat (18.46.0) gübresi ile birlikte $15 \mathrm{~kg}$ üre (\% $46 \mathrm{~N}$ ) vermiştir. Üst gübrelemede $25 \mathrm{~kg}$ üre (\%46 N) uygulamıştır. 4.Üretici, taban gübresi kullanmamış, ilk gübrelemede $28 \mathrm{~kg} /$ da üre (\%46 N), ikinci gübrelemede $27 \mathrm{~kg} / \mathrm{da}$ amonyum nitrat (\%33 N) vermiştir. 5.Üretici, taban gübresi kullanmamış olup çıkıştan sonra $25 \mathrm{~kg}$ üre (\%46 N) ve $45 \mathrm{~kg}$ Amonyum sülfat (\%21 N) kullanmıştır. Yaprak gübresi olarak \%5 Çinko (Zn) içerikli sıvı gübre 200 g/da kullanmıştır. 6.Üretici, taban gübresi kullanmamış, ilk gübrelemede $30 \mathrm{~kg} /$ da Üre (\%46 N), ikinci gübrelemede 28 kg Amonyum sülfat (\%21 N) kullanmıştır. 7.Üretici, taban gübresi kullanmamış, ilk toprak gübrelemesinde $30 \mathrm{~kg} / \mathrm{da}$ üre (\%46 N), daha sonra yaprak gübresi olarak deniz yosunu, $(0.15 .13+\mathrm{ME})$ içerikli yaprak gübresi kullanmıştır. 8.Üretici, taban gübresi olarak hexaferm organik gübresi (8.21.0) $30 \mathrm{~kg} / \mathrm{da}$, ilk gübrelemede $30 \mathrm{~kg} / \mathrm{da}$ üre (\%46 N) ve ikinci gübrelemede amonyum nitrat (\%33 N) vermiştir. Ayrıca, $200 \mathrm{~g} /$ da yaprak gübresi (10.52.10) de vermiştir. 9.Üretici, taban gübresi olarak kompoze gübre (15.15.15) kullanmıştır. İlk gübrelemede $22 \mathrm{~kg} / \mathrm{da}$ üre (\%46 N), ikinci gübrelemede $25 \mathrm{~kg} /$ da Amonyum sülfat (\%21 N) vermiştir. Ayrıca, dekara $100 \mathrm{ml}$ atılan bitki besleme ürünü (\%22 organik madde, \%6 azot, \%4 fosfor, \%4 potasyum ve mikro elementlerden) de verilmiştir. 10.Üretici, taban gübresi olarak 20-20-0 kompoze gübresini $25 \mathrm{~kg} / \mathrm{da}$ olarak uygulamıştır. Üst gübrelemede önce $28 \mathrm{~kg}$ üre (\%46 N) daha sonra $40 \mathrm{~kg} / \mathrm{da}$ amonyum sülfat (\%21 N) uygulamıştır. Ayrıca, yaprak gübresi olarak $150 \mathrm{~g} / \mathrm{da}$ Potasyum oksit $\left(\mathrm{K}_{2} \mathrm{O}\right)$ : \% 42, $400 \mathrm{~g} /$ da Bor (B): \% 3, Çinko (Zn): \%10 içerikli yaprak gübresi ve fülvik asit uygulaması yapmıştır.

Çalışmada, üreticilerin uyguladığı defoliant ve koza açtırıcı kimyasallar ise aşağıdaki gibidir. 
1. Üretici: $250 \mathrm{ml}$ Sonfinal $(480+60 \mathrm{~g} / \mathrm{l}$ Ethephon + Cyclanilide) ile $65 \mathrm{ml}$ Baystar $(119.75+59.88 \mathrm{~g} / \mathrm{l}$ Thidiazuron+Diuron), 2.üretici: $250 \mathrm{ml}$ Sonfinal $(480+60$ $\mathrm{g} / \mathrm{l}$ Ethephon + Cyclanilide) ile $30 \mathrm{ml}$ Baystar (119.75+59.88 g/l Thidiazuron+Diuron), 3.Üretici: $230 \mathrm{ml}$ Sonfinal (480 + $60 \mathrm{~g} / \mathrm{l}$ Ethephon + Cyclanilide) ile $45 \mathrm{ml}$ Baystar (119.75+59.88 g/l Thidiazuron+Diuron), 4. Üretici: 240 $\mathrm{ml} / \mathrm{da}$ Derim Extra (720 g/l Ethephon) ile $60 \mathrm{ml} / \mathrm{da}$ Doruk Ultra (120 g/I Thidiazuron + $60 \mathrm{~g} / \mathrm{I}$ Diuron), 5.Üretici: 250 $\mathrm{ml} / \mathrm{da}$ Ultio PRO SC765 (720 g/l Ethephon + $45 \mathrm{~g} / \mathrm{l}$ Cyclanilide) ile $50 \mathrm{ml} / \mathrm{da}$ Figura Ultra (120 g/l Thidiazuron + 60 g/l Diuron), 6.Üretici: $220 \mathrm{ml} / \mathrm{da}$ Finish Pro $(720 \mathrm{~g} / \mathrm{l}$ Ethephon, $45 \mathrm{~g} / \mathrm{l}$ Cyclanilide) ile $20 \mathrm{ml} / \mathrm{da}$ Finish Dropp Ultra (120 g/l Thidiazuron + $60 \mathrm{~g} / \mathrm{l}$ Diuron), 7.Üretici: $250 \mathrm{ml} / \mathrm{da}$ Son-Final (480 Ethephon $+60 \mathrm{~g} / \mathrm{L}$ Cyclanilide) $+50 \mathrm{ml} / \mathrm{da}$ Baystar (119.75 Thidiazuron + $59.88 \mathrm{~g} / \mathrm{l}$ Diuron), 8.Üretici: $200 \mathrm{ml} / \mathrm{da}$ Finish Pro (720 g/l Ethephon, $45 \mathrm{~g} / \mathrm{l}$ Cyclanilide) ile $50 \mathrm{ml} / \mathrm{da}$ Finish Dropp Ultra (120 g/l Thidiazuron + $60 \mathrm{~g} / \mathrm{l}$ Diuron), 9.Üretici: $230 \mathrm{ml} / \mathrm{da}$ Extralin Pro SC 765 (720 g/l Ethephon + $45 \mathrm{~g} / \mathrm{l}$ Cyclanilide) ile defoliant olarak $60 \mathrm{ml} / \mathrm{da}$
Fraction Ultra (119.75 g/l Thidiazuron+ $59.88 \mathrm{~g} / \mathrm{l}$ Diuron), 10.Üretici: $250 \mathrm{ml} / \mathrm{da}$ Finish Pro (720 g/l Ethephon, $45 \mathrm{~g} / \mathrm{l}$ Cyclanilide) ile $60 \mathrm{ml} / \mathrm{da}$ Finish Dropp Ultra $(120 \mathrm{~g} / \mathrm{l}$ Thidiazuron + 60 g/l Diuron) kimyasallarını uygulamıştır.

Çalışmanın yürütüldüğü ilçe/köy ve diğer kültürel uygulamalar Çizelge 1'de verilmiştir.

Çizelge 1'de, üreticilerin kültürel uygulamaları farklı zaman ve sayıda yaptıkları, ekim işleminin 22 Nisan ile 5 Haziran tarihleri arasında gerçekleştirildiği, dekarda bitki sayısının 13,698 ile 20,004 adet arasında olduğu, çapalama sayısının 1 ile 3 arasında, sulama sayısının 2 ile 3 arasında, zirai ilaçlama sayısının ise 5 ile 8 arasında değiştiği, defoliant uygulamasının 1 Eylül ile 20 Ekim tarihleri arasında \%69 ile \%86 arasında değişen koza açımında gerçekleştirildiği, hasat işleminin ise 14 Eylül ile 31 Ekim tarihleri arasında \%95 ile \%100 arasında değişen koza açımında yapıldığı görülmektedir. Çalışmada, her bir üretici tarlasında, defoliant uygulamasından hemen önce dört farklı alanda ardışık 5'er bitkide tüm yapraklar sayılmıştır. Hasattan önce ise bitkilerde kalan yeşil yapraklar sayılarak Çizelge 1. Çalışmanın yürütüldüğü ilçe/köy ve diğer kültürel uygulamalar

\begin{tabular}{|c|c|c|c|c|c|c|c|}
\hline $\begin{array}{l}\text { Üreticiler } \\
\text { İlçe/Köy }\end{array}$ & $\begin{array}{c}\text { Ekim } \\
\text { Zamanı }\end{array}$ & $\begin{array}{c}\text { Bitki } \\
\text { Say./da }\end{array}$ & $\begin{array}{l}\text { Çap. } \\
\text { Say. }\end{array}$ & $\begin{array}{l}\text { Sul. } \\
\text { Say. }\end{array}$ & $\begin{array}{l}\text { i̇laç. } \\
\text { Say. }\end{array}$ & $\begin{array}{c}\text { Defoliant Uyg. } \\
\text { Zamanı } \\
\end{array}$ & Hasat Zamanı \\
\hline $\begin{array}{l}\text { 1. Üretici } \\
\text { Efeler/Kurtuluş }\end{array}$ & 5 Mayıs & 15.715 & 1 & 3 & 7 & $\begin{array}{c}28 \text { Eylül, \%74 Koza } \\
\text { açımı }\end{array}$ & $\begin{array}{c}16 \text { Ekim, \%97 koza } \\
\text { açımı }\end{array}$ \\
\hline $\begin{array}{l}\text { 2. Üretici } \\
\text { Söke/Burunköy }\end{array}$ & 5 Haziran & 17.633 & 3 & 2 & 7 & $\begin{array}{c}20 \text { Ekim, \%69 koza } \\
\text { açımı }\end{array}$ & $\begin{array}{c}31 \text { Ekim, \%97 koza } \\
\text { açımı }\end{array}$ \\
\hline $\begin{array}{l}\text { 3. Üretici } \\
\text { Söke/Özbaşi }\end{array}$ & 28 Nisan & 17.809 & 1 & 3 & 5 & $\begin{array}{c}28 \text { Eylül, \%76 koza } \\
\text { açımı }\end{array}$ & $\begin{array}{c}6 \text { Ekim, \%95 koza } \\
\text { açımı }\end{array}$ \\
\hline $\begin{array}{l}\text { 4. Üretici } \\
\text { Koçarlı/Kasaplar }\end{array}$ & 8 Mayıs & 20.004 & 3 & 3 & 8 & $\begin{array}{c}3 \text { Ekim, \%69 koza } \\
\text { açımı }\end{array}$ & $\begin{array}{c}16 \text { Ekim, \%99 koza } \\
\text { açımı }\end{array}$ \\
\hline $\begin{array}{l}\text { 5. Üretici } \\
\text { Söke/Güllübahçe }\end{array}$ & 15 Mayıs & 19.452 & 2 & 3 & 6 & $\begin{array}{c}5 \text { Ekim \%86 koza } \\
\text { açımı }\end{array}$ & $\begin{array}{c}19 \text { Ekim, \%97 koza } \\
\text { açımı }\end{array}$ \\
\hline $\begin{array}{l}\text { 6. Üretici } \\
\text { Söke/Akçakaya }\end{array}$ & 6 Mayıs & 16.053 & 3 & 3 & 7 & $\begin{array}{c}1 \text { Eylül, \%84 koza } \\
\text { açımı }\end{array}$ & $\begin{array}{c}14 \text { Eylül, \%99 koza } \\
\text { açımı }\end{array}$ \\
\hline $\begin{array}{l}\text { 7. Üretici } \\
\text { Didim/Akyeniköy }\end{array}$ & 22 Nisan & 14.604 & 2 & 3 & 7 & $\begin{array}{c}19 \text { Eylül, \%76 koza } \\
\text { açımı }\end{array}$ & $\begin{array}{c}2 \text { Ekim, \%95 koza } \\
\text { açımı }\end{array}$ \\
\hline $\begin{array}{l}\text { 8. Üretici } \\
\text { Söke/Sarıkemer }\end{array}$ & 2 Mayıs & 13.698 & 1 & 3 & 7 & $\begin{array}{c}20 \text { Eylül, \%74 koza } \\
\text { açımı }\end{array}$ & $\begin{array}{c}5 \text { Ekim, \%97 koza } \\
\text { açımı }\end{array}$ \\
\hline $\begin{array}{l}\text { 9. Üretici } \\
\text { Söke/Yenicami }\end{array}$ & 27 Nisan & 14.909 & 2 & 3 & 6 & $\begin{array}{c}30 \text { Eylül, \%83 koza } \\
\text { açımı }\end{array}$ & $\begin{array}{c}12 \text { Ekim, \%100 koza } \\
\text { açımı }\end{array}$ \\
\hline $\begin{array}{l}\text { 10. Üretici } \\
\text { Germencik/Uzunkum }\end{array}$ & 24 Nisan & 19.180 & 2 & 3 & 8 & $\begin{array}{c}3 \text { Ekim, \%85 koza } \\
\text { açımı }\end{array}$ & $\begin{array}{c}17 \text { Ekim, \%97 koza } \\
\text { açımı }\end{array}$ \\
\hline
\end{tabular}

ve toplam yapraktan çıkarılarak dökülen yaprak sayısı saptanmıştır. Kuruyan fakat dökülmeyip bitki üzerinde asılı kalan yapraklar da kayıt altına alınmıştır. Uygulama zamanının belirlenmesi için \% koza açma oranları, yaprak sayımı yapılan 5'er bitkide yapılarak ve uygulamadan hemen önce ve hasattan hemen önce olmak üzere 2 defa koza açma oranı tespit edilmiş olup, bulunan değerler \% olarak ifade edilerek, uygulamadan sonraki sayımlar ile makinalı hasada yardımcı kimyasalların koza açımına etkisi belirlenmiştir. Çalışmanın yürütüldüğü her bir üretici tarlasında, hasat sonrası makinenin deposundan dört adet kütlü pamuk örneği alınmıştır. Örnek alımı sırasında kütlü pamuk örneklerinin nem oranları nem ölçer yardımı ile tespit edilmiştir. Hasat sonrası elde edilen kütlü pamuk örnekleri, rollergin tipi çırçır makinasında çırçırlanmıştır. Çırçırlama sonrası kütlü pamuk, lif ve çiğit olarak ikiye ayrılmış ve bunların ayrı ayrı tartımı hassas terazide yapıımıştır. Çırçır randımanı da aşağıdaki formül ile hesaplanmıştır;

Çırçır Randımanı =[Lif Ağırlığı (g)/Kütlü Ağırlığı(g)]x 100 
Çalışmada, her bir özellik için elde edilen değerler, "TARIST" istatistik analiz hazır paket programı kullanılarak tesadüf parselleri deneme desenine göre varyans analizine tabi tutulmuştur (Açıkgöz ve ark., 1994). Veri ortalamalarının karşılaştırılmasında "LSD (\%5) Testi" kullanılmıştır (Steel ve Torrie, 1980).

\section{BULGULAR VE TARTIŞMA}

Çalışmada, defoliant uygulama öncesi toplam koza sayısı, açmış koza sayısı, açık koza oranı, defoliant uygulama sonrası açık koza sayısı, açık koza oranı özelliklerine ilişkin varyans analizi kareler ortalaması Çizelge 2'de, defoliant uygulama öncesi toplam yaprak sayısı, defoliant uygulama sonrası bitki üzerinde kalan yeşil yaprak sayısı, bitki üzerinde kalan kuru yaprak sayısı, yaprak döküm oranı, çırçır randımanı ve pamuk nem içeriği özelliklerine ilişkin varyans analizi kareler ortalaması ise Çizelge 3'de verilmiştir. Çizelge 2' ve Çizelge 3'de, defoliant uygulama öncesi toplam koza sayısı, açmış koza sayısı, açık koza oranı, defoliant uygulama sonrası açık koza sayısı, defoliant uygulama öncesi toplam yaprak sayısı, defoliant uygulama sonrası bitki üzerinde kalan yeşil yaprak sayısı, bitki üzerinde kalan kuru yaprak sayısı, yaprak döküm oranı ve çırçır randımanı yönünden üretici defoliant uygulamaları arasında önemli farklılıkların olduğu, defoliant uygulama sonrası açık koza oranı ve nem içeriği özellikleri yönünden ise üretici defoliant uygulamaları arasında önemsiz farklılıkların olduğu görülmektedir. Defoliant uygulama öncesi toplam koza sayısı, açmış koza sayısı, açık koza oranı, defoliant uygulama sonrası açık koza sayısı, açık koza oranı özelliklerine ilişkin ortalama değerler ve oluşan gruplar Çizelge 4'de verilmiştir.

Çizelge 2. Defoliant uygulama öncesi toplam koza sayısı (DÖTKS), açmış koza sayısı (DÖAKS), açık koza oranı (DÖAKO), defoliant uygulama sonrası açık koza sayısı (DSAKS), açık koza oranı (DSAKO) özelliklerine ilişkin varyans analizi kareler ortalaması

\begin{tabular}{lllllll}
\hline VK & SD & DÖTKS & DÖAKS & DÖAKO & DSAKS & DSAKO \\
\hline Üretici & 9 & $1073.26^{* *}$ & $592.08^{* *}$ & $179.63^{*}$ & $958.87^{* *}$ & 14.09 \\
Hata & 30 & 123.75 & 119.60 & 75.55 & 129.26 & 13.05 \\
Genel & 39 & 342.86 & 228.64 & 99.57 & 320.71 & 13.29 \\
\hline
\end{tabular}

*: \%5 seviyesinde önemli, **: \%1 seviyesinde önemli, VK: Varyansyon Kaynağı, SD: Serbestlik Derecesi

Çizelge 3. Defoliant uygulama öncesi toplam yaprak sayısı (DÖTYS), defoliant uygulama sonrası bitki üzerinde kalan yeşil yaprak sayısı (DSYYS), bitki üzerinde kalan kuru yaprak sayısı (DSKYS), yaprak döküm oranı (DSYDO), çırçır randımanı (ÇR) ve pamuk nem içeriği (Nem) özelliklerine ilişkin varyans analizi kareler ortalaması

\begin{tabular}{llllllll}
\hline VK & SD & DÖTYS & DSYYS & DSKYS & DSYDO & ÇR & Nem \\
\hline Üretici & 9 & $11164.13^{* *}$ & $681.26^{*}$ & $2859.94^{* *}$ & $1028.89 * *$ & $5.56^{* *}$ & 0.10 \\
Hata & 30 & 1511.09 & 224.74 & 140.17 & 109.55 & 0.49 & 0.04 \\
Genel & 39 & 3738.71 & 332.86 & 767.81 & 321.71 & 1.66 & 0.06
\end{tabular}

*: \%5 seviyesinde önemli, **: \%1 seviyesinde önemli, VK: Varyansyon Kaynağı, SD: Serbestlik Derecesi

Çizelge 4. Defoliant uygulama öncesi toplam koza sayısı (DÖTKS), açmış koza sayısı (DÖAKS), açık koza oranı (DÖAKO), defoliant uygulama sonrası açık koza sayısı (DSAKS), açık koza oranı (DSAKO) özelliklerine ilişkin ortalama değerler ve oluşan gruplar

\begin{tabular}{llllll}
\hline Üreticiler & DÖTKS (adet/bitki) & DÖAKS (adet/bitki) & DÖAKO (\%) & DSAKS (adet/bitki) & DSAKO (\%) \\
\hline 1. Üretici & $18.60 \mathrm{a}^{*}$ & $14.05 \mathrm{a}$ & $75.10 \mathrm{ab}$ & $18.05 \mathrm{a}$ & 96.77 \\
2. Üretici & $15.85 \mathrm{ab}$ & $10.95 \mathrm{abcd}$ & $69.32 \mathrm{~b}$ & $15.40 \mathrm{ab}$ & 97.03 \\
7. Üretici & $15.85 \mathrm{ab}$ & $12.00 \mathrm{abc}$ & $75.83 \mathrm{ab}$ & $15.10 \mathrm{abc}$ & 95.50 \\
10. Üretici & $15.40 \mathrm{ab}$ & $13.15 \mathrm{ab}$ & $86.24 \mathrm{a}$ & $14.95 \mathrm{abc}$ & 96.75 \\
8. Üretici & $14.15 \mathrm{bc}$ & $10.55 \mathrm{bcd}$ & $74.45 \mathrm{ab}$ & $13.50 \mathrm{bcd}$ & 94.50 \\
9. Üretici & $12.00 \mathrm{~cd}$ & $10.00 \mathrm{bcde}$ & $83.43 \mathrm{a}$ & $11.85 \mathrm{cde}$ & 98.50 \\
3. Üretici & $11.45 \mathrm{cde}$ & $8.75 \mathrm{def}$ & $75.92 \mathrm{ab}$ & $10.80 \mathrm{def}$ & 94.10 \\
5. Üretici & $10.80 \mathrm{de}$ & $9.35 \mathrm{cdef}$ & $86.28 \mathrm{a}$ & $10.55 \mathrm{def}$ & 97.00 \\
4. Üretici & $9.35 \mathrm{de}$ & $6.50 \mathrm{f}$ & $69.14 \mathrm{~b}$ & $9.30 \mathrm{ef}$ & 99.50 \\
6. Üretici & $8.45 \mathrm{e}$ & $7.15 \mathrm{ef}$ & $85.38 \mathrm{a}$ & $8.40 \mathrm{f}$ & 99.50 \\
\hline LSD (\%5) & 3.21 & 3.16 & 12.56 & 3.28 & \\
\hline
\end{tabular}

*Aynı harfle gösterilen ortalamalar arasında, 0.05 olasılık sınıınna göre önemli farklılık yoktur. 
Çizelge 4'de, defoliant uygulaması öncesi, toplam koza sayısının en yüksek 1. üreticide 18.60 adet/bitki, en düşük koza sayısının ise 6 . üreticide 8.45 adet/bitki olduğu, defoliant uygulama öncesi açık koza sayısı değerinin en yüksek 1. üreticide 14.05 adet/bitki, en düşük 4. üreticide 6.50 adet/bitki olduğu, defoliant uygulama öncesi açmış koza oranının en yüksek 5. üreticide $\% 86.28$, en düşük koza açım oranının ise 4. ve 2. üreticide $\% 69.14$ olduğu, defoliant uygulama sonrası açık koza sayısının en fazla 18.05 adet/bitki ile 1 . üreticide, en az ise 8.40 adet/bitki ile 6 . üreticide olduğu, defoliant uygulama sonrası açık koza oranlarında en yüksek değerin \%99.50 ile 4. ve 6. üreticide, en düşük koza açma oranının ise 3. üreticide \%94.10 olduğu görülmektedir. Çalışmada, defoliant uygulama öncesi toplam koza sayısı değerleri ortalama olarak 8.45-18.60 adet/bitki, defoliant sonrası açmış koza sayısı değerleri ise 8.40-18.05 olarak bulunmuştur. Her iki dönemde de üreticiler arasında koza sayısı yönünden önemli farklılıklar vardır.

Genel olarak Aydın ilinde defoliant uygulamasının koza açım oranı \%65 seviyesinden sonra yapıldığı söylenebilir. Üreticilerde saptanan defoliant uygulamasındaki koza açım oranı değerleri \%69.14 - \%86.26 arasında değişim göstermektedir. Uygulama öncesi koza açım oranı yönünden üreticiler arasında önemli farklılıklar bulunmaktadır. Defoliant uygulama öncesi ve sonrası koza sayısı ve defoliant uygulama öncesi koza açım oranlarında üreticiler arasında farklılıkların; üreticilerin birbirinden bağımsız olarak uygulamış oldukları kültürel işlemlerden, hastalık ve zararlılardan, toprak özelliklerinden, ekim ile hasat tarihleri arasındaki değişimlerden ve bitki sıklığından kaynaklanabilmektedir. Defoliant sonrası koza açım oranları arasında da istatistiksel olarak fark olmadığı tespit edilmiştir. Koza açım oranları üreticiler arasında \%99.50 \%94.10 arasında değişim göstermiştir. Aydın ilinde 10 üreticiden; 4'ü Son Final (480 Ethephon + $60 \mathrm{~g} / \mathrm{l}$ Cyclanilide), 3'ü Finish Pro (720 g/l Ethephon, $45 \mathrm{~g} / \mathrm{l}$ Cyclanilide), 1'i Derim Extra (720 g/l Ethephon), 1'i Extralin Pro SC765 (720 g/l Ethephon + 45 g/l Cyclanilide), 1'i Ultio Pro (720 g/l Ethephon, $45 \mathrm{~g} / \mathrm{l}$ Cyclanilide)'yu tercih ettiği kayıt altına alınmıştır. Kimyasalın uygulanması ile hasat arası süresi genel olarak 7-10 gün arasında olan defoliant ve koza açtırıcılar için Aydın ilinde ortalama bekleme süresi 13.1 gün olduğu tespit edilmiştir.

Çalışmada, defoliant sonrası açmış koza sayısı değerleri diğer bir deyişle toplanan kaza sayısı 8.40-18.05 olarak bulunmuştur. Elde edilen bu bulgu; aşağıda verilen daha önce yapılmış birçok çalışma ile benzerlik göstermektedir. Çopur ve ark. (2010), yapmış olduğu çalışmada 15.53 20.92 adet/bitki de koza olduğunu, çiçeklenmeden sonraki 90. günde uygulanan defoliant ile daha fazla koza sayısına ulaşıldığını belirtmiştir. Baran ve Kaynak (2015), ikinci ürün
KABAK R, KAYNAK MA

farklı pamuk çeşitlerinde toplam koza sayısını ortalama 6.15-11.56 olarak tespit etmiş, ekim zamanı geciktikçe koza sayısının azaldığını belirtmiştir. Karademir ve ark. (2007), koza sayısını 13.33-15.80 olduğunu bildirmiştir.

Kaynak ve ark. (1999), 60cc/da Dropp Ultra uygulamasını 5 farklı koza açım oranında (\%40, \%50, \%60, \%70, \%80) uygulamış ve Nazilli 84 çeşidi etkilenmezken, Deltapine 5690 çeşidinde koza sayısında önemli farklılıklar olduğunu (20.33-10.37) tespit etmişlerdir. Qamar ve ark. (2016), koza sayısının bitki başına 31.0-18.5 olduğunu ve ekim tarihinin istatistiksel olarak koza sayısı üzerinde önemli etkisi olduğunu belirtmişlerdir.

Görmüş ve ark. (2017), hasata yardımcı kimyasalların uygulama zamanının koza sayısına etkisi olduğunu ve yıllara göre koza sayısında da önemli farklılıklar olduğunu belirtmiştir.2013-2014 yıllarında yapılan sayımlarda kontrolde 22.8-23.0 koza bulunurken, \%80 koza açımından sonraki uygulamada \%19.3-20.2 koza olduğu saptanmıştır. Haliloğlu ve ark. (2020), 10 Mayıs'ta ekilen pamuklarda 19.93-19.35 koza/bitki ve 10 Haziran'da ekilen pamuklarda da 13.52-13.90 koza/bitki olduğunu belirtmiştir. Açılmış koza sayısı 10 Mayıs'ta ekilen pamuklarda 16.88-16.20 adet/bitki ve 10 Haziran'da ekilen pamuklarda ise 12.9712.41 adet/bitki olarak tespit etmişlerdir. Açmamış koza sayısı da 1.97 ile 2.97 adet/bitki arasında tespit edilmiştir.

Defoliant uygulama öncesi toplam yaprak sayısı, defoliant uygulama sonrası bitki üzerinde kalan yeşil yaprak sayısı, bitki üzerinde kalan kuru yaprak sayısı, yaprak döküm oranı, çırçır randımanı ve pamuk nem içeriği özelliklerine ilişkin ortalama değerler ve oluşan gruplar Çizelge 5 'de verilmiştir. Çizelge 5'de, en fazla toplam yaprak sayısının 56.15 adet/bitki ile 7. üreticide, en az yaprak sayısının ise 24.15 adet/bitki ile 6 . üreticide olduğu, defoliant uygulama sonrası bitki üzerinde asılı kalan yeşil yaprak sayısının en fazla 7. üreticide (8.95 adet/bitki) en düşük yeşil yaprak sayısının ise 4. üretici (1.20 adet/bitki) de olduğu, defoliant uygulama sonrası bitkide asılı kalan kuru yaprak sayısı değerlerine göre en çok kuru yaprağın 4. üreticide (18.90 adet/bitki), en düşük kuru yaprak sayısının ise 6 . üreticide (1.60 adet/bitki) olduğu, en yüksek yaprak döküm oranının 6. üreticide (\%86.85), en düşük yaprak döküm oranının ise 4. üreticide (\%29.25) olduğu görülmektedir. Defoliant doz uygulaması gerektiği şekilde yapılmalıdır. Defoliant dozuna bütün üreticiler aynı önemi vermiş olsaydı yeşil yaprak, kuru yaprak ve yaprak döküm oranları arasında önemli farklılıkların olmaması gerekirdi, farklılıklar üreticilerden bazılarının defoliant uygulama işlemini istenildiği şekilde yapmadıklarını göstermektedir.

Defoliant uygulama öncesinde ortalama bitki başına yaprak sayısının 24.15 ile 56.15 adet arasında değiştiği saptanmıştır. 
Çizelge 5. Defoliant uygulama öncesi toplam yaprak sayısı, defoliant uygulama sonrası bitki üzerinde kalan yeşil yaprak sayısı, bitki üzerinde kalan kuru yaprak sayısı, yaprak döküm oranı, çırçır randımanı ve pamuk nem içeriği özelliklerine ilişkin ortalama değerler ve oluşan gruplar

\begin{tabular}{lllllll}
\hline Üreticiler & $\begin{array}{l}\text { DÖTYS } \\
\text { (adet/bitki) }\end{array}$ & $\begin{array}{l}\text { DSYY } \\
\text { (adet/bitki) }\end{array}$ & $\begin{array}{l}\text { DSKYS } \\
\text { (adet/bitki) }\end{array}$ & $\begin{array}{l}\text { DSYDO } \\
\text { (\%) }\end{array}$ & $\begin{array}{l}\text { Çırçır } \\
\text { Randımanı (\%) }\end{array}$ & $\begin{array}{l}\text { Nem İceriği } \\
\text { (\%) }\end{array}$ \\
\hline 7. Üretici & $56.15 \mathrm{a}$ * & $8.95 \mathrm{a}$ & $3.30 \mathrm{~cd}$ & $78.75 \mathrm{ab}$ & $39.35 \mathrm{de}$ & 7.50 \\
1. Üretici & $50.40 \mathrm{ab}$ & $8.10 \mathrm{a}$ & $1.75 \mathrm{~d}$ & $80.25 \mathrm{ab}$ & $40.45 \mathrm{bc}$ & 7.50 \\
10. Üretici & $48.70 \mathrm{ab}$ & $5.20 \mathrm{ab}$ & $5.90 \mathrm{bc}$ & $76.00 \mathrm{ab}$ & $38.37 \mathrm{ef}$ & 7.75 \\
8. Üretici & $43.55 \mathrm{bc}$ & $5.05 \mathrm{ab}$ & $5.80 \mathrm{c}$ & $75.25 \mathrm{ab}$ & $40.62 \mathrm{bc}$ & 7.50 \\
3. Üretici & $37.05 \mathrm{~cd}$ & $5.00 \mathrm{ab}$ & $1.65 \mathrm{~d}$ & $81.50 \mathrm{ab}$ & $39.77 \mathrm{~cd}$ & 7.57 \\
9. Üretici & $35.40 \mathrm{~cd}$ & $1.35 \mathrm{~b}$ & $9.30 \mathrm{~b}$ & $70.00 \mathrm{~b}$ & $41.05 \mathrm{ab}$ & 7.42 \\
2. Üretici & $31.95 \mathrm{de}$ & $3.65 \mathrm{~b}$ & $2.70 \mathrm{~cd}$ & $78.07 \mathrm{ab}$ & $41.25 \mathrm{ab}$ & 7.52 \\
5. Üretici & $30.90 \mathrm{de}$ & $4.65 \mathrm{ab}$ & $2.95 \mathrm{~cd}$ & $74.50 \mathrm{ab}$ & $38.22 \mathrm{f}$ & 7.95 \\
4. Üretici & $28.30 \mathrm{de}$ & $1.20 \mathrm{~b}$ & $18.90 \mathrm{a}$ & $29.25 \mathrm{c}$ & $39.77 \mathrm{~cd}$ & 7.55 \\
6. Üretici & $24.15 \mathrm{e}$ & $1.55 \mathrm{~b}$ & $1.60 \mathrm{~d}$ & $86.85 \mathrm{a}$ & $41.72 \mathrm{a}$ & 7.45 \\
\hline LSD (\%5) & 11.23 & 4.33 & 3.42 & 15.12 & 1.01 & \\
\hline
\end{tabular}

*Aynı harfle gösterilen ortalamalar arasında, 0.05 olasılık sınırına göre önemli farklıık yoktur. DÖTYS: Defoliant uygulama öncesi toplam yaprak sayıSı, DSYYS: Defoliant uygulama sonrası yeşil yaprak sayısı, DSKYS: Defoliant uygulama sonrası kuru yaprak sayıSı, DSYDO: Defoliant uygulama sonrası yaprak döküm oranı

Yaprak sayısı yönünden üreticiler arasında farklılığın olmasına, uygulanan kültürel işlemler ile çevresel faktörler etkili olduğu düşünülmektedir. Çalışmada, elde edilen yaprak sayısı değerleri, Sokat ve Gürel (2010)'un yaprak sayısı (45.2 - 60.2) değerleri ile benzerlik göstermektedir.

Yaprak döküm oranları yönünden de üreticiler arasında önemli farklılık meydana gelmiştir. Yaprak döküm oranları arasında tek bir üretici haricinde \%86.85 ile \%70.00' lik yaprak döküm oranlarına ulaşılmıştır. 4. üreticide ise defoliant içeriği, kullanılan doz miktarı veya bitki sıklığından kaynaklı olarak en fazla kuruyarak bitki üzerinde asılı kalan yaprak sayısı değerine ulaşılmıştır. Yaprak döküm oranı da \%29.25 olarak tespit edilmiştir. 4.Üretici'nin yaprak döküm oranının diğerlerine göre düşük olması, defoliantın verimli çalışmadığını göstermektedir. Üreticiler arasında da bitkilerin en sık olduğu tarlada $(20,004$ bitki/dekar), defoliant dozu olarak $240 \mathrm{~g} / \mathrm{l}$ Derim Extra $(720 \mathrm{~g} / \mathrm{l}$ Ethephon) ile $60 \mathrm{~g} / \mathrm{l}$ Doruk Ultra (120 g/I Thidiazuron + 60 $\mathrm{g} / \mathrm{I}$ Diuron) uygulanmıştır. 4.üretici tarlasında, yaprak döküm oranının düşük olmasına, defoliant uygulamasından 1 gün sonraki yağışın da etkili olduğu düşünülmektedir (Anonim, 2019).

Çalışmada elde edilen, \%29.5-\%86.85 arasında değişen yaprak döküm oranı bulgularıyla; Nelson ve Hart (1994)'ın defoliant uygulamalarında yaprak döküm oranlarının \%9295 seviyelerine ulaştığını belirten çalışması, Tülemen ve Kaynak (2016)'nın defolianttan sonraki 21.Günde yaprakların \%94-97'sinin döküldüğünü belirten çalışmasıyla kısmen benzerlik, Nelson ve Hart (1995)'in Upland pamukların dadefolizasyondan sonraki 7. Günde yaprak döküm oranının \%35-78 arasında ve 14. Günde \%47-93 arasında olduğunu belirten çalışmasıyla ise benzerlik göstermektedir. Görmüş ve ark. (2017), \%40 koza açımından sonra uygulanan defoliantın daha fazla yaprak döktüğünü ve uygulamadan sonra 28. Günde en düşük yaprak sayılarına ulaşıldığı belirtilmektedir. 2013 ve 2014 verilerine göre 14. Günde kontrolde 93.0-92.3 yeşil yaprak bulunurken, \%80 koza açımından sonraki sayımlarda 59.858.9 yeşil yaprak kaldığı belirtilmiştir.

Çopur ve ark. (2010), en uygun defoliant uygulama zamanının çiçeklenmeden sonraki 75. gün olduğu sonucuna varmıştır. Erken uygulamaların koza kayıplarına neden olduğunu ve geç uygulamaların da hava sıcaklığının optimum $\left(12.7-15.6^{\circ} \mathrm{C}\right)$ değerden aşağı düştüğünden dolayı yaprak dökülmesine ve koza açımına olumsuz etki yaptığını belirtmiştir. Çiçeklenmeden sonraki 60,75 ve 90 . günlerde yaptığı defoliant uygulamaları ile bitki üzerine kalan yaprak sayılarını 2001 yılında 3, 7, 25 ve 2002 yılında 2, 10, 35 olarak tespit etmiştir. Yaprak sayımı ile elde edilen bulguların diğer araştırıcıların bulgularından farklı olmasına; materyal, uygulanan kültürel işlemler, bitki sıklığı, defoliant uygulama şekli, zamanı ve dozunun etkili olduğu düşünülmektedir. Çizelge 5 'de, en yüksek çırçır randımanının 6.üreticide (\%41.72), en düşük çırçır randımanının ise 5 . üreticide (\%38.22) olduğu görülmektedir. Haliloğlu ve ark. (2020)'nin, \%41.43-44.33 olan randıman verileri, bulduğumuz verilerden kısmen yüksektir. Çopur ve Yuka (2016), çırçır randımanının çeşide göre değişebildiğini fakat yıllara göre değişmediğini belirtmişlerdir. Üretici defoliant uygulamalarının çırçır randımanı üzerine oluşturduğu etkinin önemli olduğu tespit edilmiştir. 
Mert ve ark. (1999), Ataş (2008), Larson ve ark. (2005), Beyyavaş (2019), Qamar ve ark. (2016)'nın defoliant uygulamanın çırçır randımanına etkisi olduğunu belirten çalışmaları ile elde edilen bulgular uyum içerisindendir.

Kaynak ve ark. (1999), Tülemen ve Kaynak (2016), Sokat ve Gürel (2010), Karaman (2019), Sadık ve Kaynak (2017)’ın defoliant uygulamasının çırçır randımanına etkisinin olmadığını belirten çalışmalar ise bulgularımızdan farklılık göstermektedir. Çizelge 5'de, farklı lokasyonlardan alınmış olan pamuk örneklerinin nem içerikleri en yüksek 5 . Üretici (\%7.9) ve ardından 10. Üretici (\%7.75) gelmektedir. Nem içeriği en düşük olarak da 9. Üretici (\%7.42) ile 6. Üretici (\%7.45) gelmektedir. Örneklerin hepsi depolama için uygun neme sahiptir. \%5-15 arası değişen nem oranlarının pamukta lif kalitesi üzerine etkisini belirlemek için yapılan çalışmada, parlaklık (Rd) ve sarılık $(+b)$ değerlerinin diğer özelliklere göre daha çok etkilendiği belirtilmiştir. En uygun pamuk balya depolama neminin ise \%7.5 olduğu belirtilmiştir (Anthony, 2003). Çalışmada, defoliant uygulamasının kütlü pamuk nem içeriğine etkisinin olmadığı saptanmıştır. El edilen bu bulgu, Sokat ve Gürel (2010)'nun, ikinci ürün pamuk üretiminde kullanılan defoliantın lif nemine istatistiksel olarak etkisi olduğunu ve lif nem değerlerinin \%8.0-9.7 arasında olduğu belirten çalışmasıyla benzerlik göstermemektedir. Araştırmalar arasındaki farklılıkların, materyal, uygulanan kültürel işlemler ve çevresel faktörlerden kaynaklandığı düşünülmektedir.

\section{SONUÇ}

Çalışma alanı gerek iklim gerekse toprak özellikleri yönünden oldukça homojen bir yapıdadır. Buna karşın, çeşit aynı olmasına karşın, defoliant uygulama öncesi koza sayısı ve yaprak sayısı özellikleri yönünden üreticiler arasında önemli farklılıkların olması, üreticilerin üretim tekniklerini ve ekim sıklığını aynı düzeyde uygulamadıklarını göstermektedir. Aynı şekilde defoliant uygulama sonrası yeşil yaprak sayısı, bitki üzerinde kalan kuru yaprak sayısı ve yaprak döküm oranında üreticiler arasında önemli farklılık olması, üreticilerin defoliant uygulama şekline, uygulama zamanına ve özellikle uygulama dozuna aynı düzeyde önem vermemelerinden kaynaklanmaktadır. Çalışmada, bazı üreticilerin defoliant uygulama işlemini gerektiği şekilde yapmadığı saptanmıştır. Sonuç olarak, makinalı pamuk hasadında gerek hasat kayıplarının gerekse kalitenin düşmemesi için defoliant uygulama işlemi hakkında pamuk üreticilerinin eğitilmesinin, üreticilerimiz ve ülkemiz ekonomisi yönünden yararlı olacaktır.

\section{KAYNAKLAR}

Açıkgöz N, Akaş ME, Moghaddam AF, Özcan K (1994) TARIST. PC'ler için bir Agro-istatistik Programı. Tarla Bitkileri Kongresi, 25-29 Nisan, İzmir, s. 264-267

Anonim (2018) TUik verileri [www.tuik.gov.tr], Erişim Tarihi: 19.04.2020
Anonim (2019). Aydın ili iklim Değerleri. Devlet Meteoroloji İşleri Aydın Bölge İstasyonu Kayıtları, Aydın.

Anthony WS (2003) Impact of Moisture on Baled Cotton. ASAE Paperno. 031167, 39 pp. American Society of Agricultural Engineers, St. Joseph, MI.

Ataş E (2008) Farklı Zamanlarda Ekilen Pamukta Değişik Defoliyant Uygulama Zamanlarının Verim ve Kaliteye Etkisi. Yüksek Lisans Tezi, Çukurova Üniversitesi Adana.

Baran FO, Kaynak MA (2015) İkinci Ürün Koşullarında Farklı Ekim Zamanlarının Pamuğun (Gossypium hirsutum L.) Bazı Koza ve Lif Teknolojik Özellikleri Üzerine Etkisi. Adnan Menderes Üniversitesi Ziraat Fakültesi Dergisi, 12(1): 1-8.

Beyyavaş V (2019) The Effect of Different Harvest Aiding Chemicals on Yield and Yield Components of Cotton (Gossypium hirsutum L.). Applied Ecology and Environmental Research, 17(2): 2733-2743.

Çopur O, Demirel U, Polat R, Gür MA (2010) Effect of Different Defoliants and Application Times on the Yield and Quality Components of Cotton in Semi-Arid Conditions. African Journal of Biotechnology, 9(14): 2095-2100.

Çopur O, Yuka A (2016) Buğday Sonrası İkinci Ürün Olarak Yetiştirilen Pamuk (Gossypium hirsutum L.) Çeşitlerinde Verim ve Verim Unsurlarının Belirlenmesi. Yüzüncü Yıl Üniversitesi Tarım Bilimleri Dergisi, 26(2): 245-253.

Görmüş O, Kurt F, Sabagh AE (2017) Impact of Defoliation Timings and Leaf Pubescence on Yield and Fiber Quality of Cotton. Journal of Agricultural Science and Technology, 19(5): 903-915.

Haliloglu H, Cevheri Ci, Beyyavaş V (2020) The Effect of Defoliant Application on Yield and Yield Components of Some Cotton (Gossypium hirsutum L.) Cultivars at Timely and Late Sowing. International Journal of Agriculture, Environment and Food Sciences, 4(2): 157-164.

Karademir E, Karademir C, Basbag S (2007) Determination The Effect of Defoliation Timing on Cotton Yield And Quality. Journal of Central European Agriculture, 8(3): 357-362.

Karaman MŞ (2019) Farklı Zaman ve Dozda Uygulanan Yaprak Döktürücülerin Pamuğun (Gossypium hirsutum L.) Verim ve Kalite Özelliklerine Etkisi. Yüksek Lisans Tezi, Mustafa Kemal Üniversitesi, Hatay.

Kaynak MA, Ünay A, Başal H, Serter E (1999) Pamukta (Gossypium hirsutum L.) Yaprak Döktürücü Uygulama Zamanının Önemli Tarımsal Ve Lif Kalite Özelliklerine Etkisinin Saptanması. Türkiye III. Tarla Bitkileri Kongresi, Adana, 15 Kasım 
Larson J, Gwathmey O, Hayes RM (2005) Effects of Defoliation Timing and Desiccation on Net Revenues from Ultra-Narrow-Row Cotton. The Journal of Cotton Science, (9): 204-224.

Mert M, Çalışkan ME, Günel E (1999) Yaprak Döktürücü Uygulamasının Pamuğun (G. hirsutum L.) Verim ve Lif Özelliklerine Etkisi. MKÜ Ziraat Fakültesi Dergisi, 4(12-1999): 1-12.

Nelson JM, Hart GL (1994) Defoliation Research on Upland and Pima Cotton at the Maricopa Agricultural Center in 1994. College of Agriculture, University of Arizona, Cotton: A College of Agriculture Report.

Nelson JM, Hart GL (1995) Effect of Combinations of Accelerate and other Defoliants on Defoliation and Yield of Pima and Upland Cotton. College of Agriculture, University of Arizona, Cotton: A College of Agriculture Report.

Qamar R, Atique-ur-Rehman Javeed HMR, Saqib M, Shoaib M, Ali A, Ali M (2016) Influence Of Sowing Time On
Cotton Growth, Yield And Fiber Quality. International Journal of Biology and Biotechnology, 13(1): 59-67.

Sadık FG, Kaynak MA (2017) İkinci Ürün Koşullarında Ekim Sıklığının Pamuğun (Gossypium hirsutum L.) Verim, Verim Unsurları Ve Lif Özellikleri Üzerine Etkisi. Adnan Menderes Üniversitesi Ziraat Fakültesi Dergisi, 14(1): 39-44.

Sokat Y, Gürel A (2010) Researches on Effects of Defoliant Applications on Yield, Fiber And Seed Quality in Second Crop Cotton (Gossypium hirsutum L.). Anadolu Ege Tarımsal Araştırma Enstitüsü Dergisi, 20(1): 91110.

Steel R, Torrie J (1980) Principles and Procedures of Statistics: A Biometrical Approach. 2nd Ed. McGraw Hill, USA.

Tülemen AS, Kaynak MA (2016) İkinci Ürün Pamukta (Gossypium hirsutum L.) Yaprak Döktürücü Kimyasalların Verim ve Kalite Özellikleri Üzerine Etkisi. Adnan Menderes Üniversitesi Ziraat Fakültesi Dergisi, 13(1):115-120. 